\title{
A DISCUSSÃO DE CONTROVÉRSIAS SOCIOCIENTÍFICAS NA FORMAÇÃO DE PROFESSORES
}

\section{Teacher training and discussion about sociocientific issues}

\author{
Cecília Galvão ${ }^{1}$ \\ Pedro Reis ${ }^{2}$ \\ Sofia Freire ${ }^{3}$
}

\begin{abstract}
Resumo: A promoção da compreensão da natureza da ciência constitui um dos eixos fundamentais dos currículos de ciências actuais, procurando que os alunos entendam a produção do conhecimento científico e tomem decisões sobre assuntos de base científica com impacto directo na sua vida. Contudo, a investigação demonstra que os professores não integram esta vertente no seu ensino, comprometendo as aprendizagens dos alunos sobre esta temática. Num outro sentido, a investigação atribui potencialidades à discussão de assuntos sociocientíficos controversos na escola na construção de uma imagem de ciência mais real. Com este estudo, pretende-se compreender como é que um conjunto de 29 professores-formandos, de um mestrado em Educação, avalia as potencialidades deste tipo de metodologia. Apesar das avaliações bastante positivas, constata-se a necessidade de continuar a apoiar estes professores na implementação destas actividades com os seus alunos de modo a desenvolverem o conhecimento necessário à sua implementação.
\end{abstract}

Palavras-chave: Formação de professores. Ensino de Ciências. Discussão. Controvérsias sócio-científicas.

\begin{abstract}
Nowadays, one of the main goals of science curricula is to promote a deep understanding about the nature of science. Particularly, it aims at facilitating students' understanding about the construction of scientific knowledge and decision making concerning scientific issues with a direct impact on their lives. However, research shows that teachers do not explore this dimension in their teaching, comprising students' learning about controversial issues. Despite this state of affairs, research also shows the potentiality of using discussion about controversial socio-scientific issues for developing a more real image of science. The goal of the present study is to understand how a group of 29 teachers enrolled in a Master in Education, appraises this teaching methodology. Despite very positive evaluations from the teachers, this study illuminates the need keep on supporting teachers in their use of discussions in the classroom.
\end{abstract}

Keywords: Teacher education. Science education. Discussion. Socio-scientific issues.

\footnotetext{
${ }^{1}$ Agregação em Educação, especialidade Didáctica das Ciências. Docente, Instituto de Educação, Universidade de Lisboa. Lisboa, Portugal. <cgalvao@ie.ul.pt>

${ }^{2}$ Doutora em Educação, especialidade Didáctica das Ciências. Docente, Instituto de Educação, Universidade de Lisboa. Lisboa, Portugal. <preis@ie.ul.pt>

${ }^{3}$ Doutora em Educação, especialidade Psicologia Educacional. Investigadora, Instituto de Educação, Universidade de Lisboa. Lisboa, Portugal.<asraposo@ie.ul.pt>

${ }^{1}$ Instituto de Educação da Universidade de Lisboa

Alameda da Universidade

1649-013 - Lisboa, Portugal 


\section{Introdução}

Nos últimos trinta anos, o slogan Ciência-Tecnologia-Sociedade (CTS) (na sua versão original em língua inglesa: Science-Technology-Society - STS) tem congregado os esforços de educadores de todo o mundo em torno do objectivo de alterar o status quo da educação em ciência (AIKENHEAD, 2003; ZIMAN, 1994). Este slogan pretende desencadear a substituição do currículo convencional de ciência (centrado na preparação para cursos universitários e considerado pouco interessante e relevante pelos alunos) por um currículo centrado no desenvolvimento de conhecimentos, capacidades e atitudes úteis para a vida diária dos alunos e preocupado com a responsabilidade social em processos colectivos de tomada de decisão sobre assuntos relacionados com ciência e tecnologia (AIKENHEAD, 2002).

A maioria dos currículos CTS apresenta, assim, quatro objectivos comuns: a) aumentar a literacia científica dos cidadãos; b) despoletar o interesse dos alunos pela ciência e pela tecnologia; c) estimular o interesse pelas interacções entre a ciência, a tecnologia e a sociedade; e d) desenvolver nos alunos capacidades de pensamento crítico, raciocínio lógico, resolução criativa de problemas e, especialmente, de tomada de decisões (AIKENHEAD, 1994; SOLOMON, 1993). Pedretti (2003), numa reflexão sobre a educação Ciência Tecnologia SociedadeAmbiente (CTSA), apresenta uma síntese do que considera ser os seus princípios orientadores:

1. A contribuição para o desenvolvimento sustentável do planeta através do estudo da utilização sistemática de recursos e da consideração das necessidades humanas a longo prazo;

2. A compreensão dos processos de tomada de decisão a nível governamental e empresarial;

3. A promoção do raciocínio moral e ético acerca da ciência;

4. A compreensão e a discussão da dimensão política da ciência;

5. O exercício de capacidades intelectuais e éticas na determinação dos aspectos positivos e negativos do desenvolvimento científico e tecnológico e no reconhecimento das forças políticas e sociais que governam o desenvolvimento e a distribuição dos conhecimentos e artefactos científicos e tecnológicos;

6. A capacitação dos cidadãos para uma acção responsável na transformação da sociedade; e

7. A compreensão da natureza da ciência e das suas interacções com a tecnologia e a sociedade.

A compreensão da natureza da ciência é um aspecto considerado, hoje em dia, fundamental no ensino das ciências. Se não se valorizar, nos currículos, a dimensão natureza da ciência, os alunos vão continuar a aprender ciências de uma forma descontextualizada, que não lhes vai permitir compreender de forma aprofundada o conhecimento científico produzido e usar esse conhecimento para tomar decisões pessoais e sociais informadas (McCOMAS, 2000). Segundo Reis e Galvão (2004), a compreensão da ciência é essencial para permitir aos alunos participarem em debates e em processos de tomada de decisão, contribuindo para a construção de uma sociedade mais democrática onde todos podem ter uma voz. Conhecer as diversas dimensões da ciência (histórica, filosófica, psicológica e sociológica), bem como as interacções que estas estabelecem entre si e a influência que têm na evolução do conhecimento científico, é fundamental para desenvolver uma compreensão complexa sobre a natureza da ciência (OSBORNE, 2000; ZIMAN, 1984). Existem inúmeras formas de facilitar essa compreensão, nomeadamente, o envolvimento dos alunos na discussão de questões problemáticas 
actuais de base científica. O objectivo desta abordagem é promover o desenvolvimento de conceitos, competências e atitudes considerados necessários a uma cidadania activa e ilustrar a dimensão social da ciência e o seu funcionamento sob influências sociais internas e externas (ZIMAN, 1994).

A escolha da discussão como veículo de aprendizagem reflecte, de forma explícita ou implícita, concepções sobre a natureza do conhecimento, a importância da autonomia intelectual e da colaboração social, bem como valores políticos relacionados com a construção de uma sociedade democrática (BRIDGES, 1988; PARKER; HESS, 2001; REIS, 2004, 2008a, 2009). Segundo uma concepção epistemológica interaccionista, a discussão é considerada a base do pensamento (DOISE; MUGNY; PERRET-CLERMONT, 1975; VYGOTSKY, 1978), sendo que os sujeitos constroem os seus instrumentos sociocognitivos a partir da interiorização de experiências e progridem intelectualmente através de interacções com outros indivíduos. Desta forma, os nossos conhecimentos e decisões têm uma origem externa, formando-se a partir dos intercâmbios de linguagem estabelecidos nos múltiplos contextos do dia-a-dia: em casa, na rua, nos programas de televisão, nos jornais, na rádio, nas salas de aula, nas reuniões formais e informais, entre outros. Para além de alargar o nível de compreensão individual, pelo contacto com as interpretações e a experiência de vida dos outros, a discussão é também um veículo potencial de promoção de valores da democracia, de respeito e da tolerância. A discussão sustenta a democracia e a cidadania, ao assentar num processo não violento de tomada de decisões, que passa pelo reconhecimento e superação de divergências, e ao promover a coesão dos grupos em torno de objectivos ou problemas comuns (BROOKFIELD; PRESKILL, 1999; GUTMANN; THOMPSON, 1996). Com efeito, a discussão requer uma atitude de respeito pelas opiniões dos diferentes participantes que é incompatível com atitudes autoritárias e envolve, inclusivamente, algum cepticismo quanto à autoridade.

Assim, a discussão de assuntos sociocientíficos controversos nas aulas de ciências tem sido amplamente proposta em virtude das suas eventuais potencialidades. $\mathrm{O}$ recurso a problemas actuais e relevantes suscita o interesse e a participação activa dos alunos, facilita o desenvolvimento de competências necessárias à resolução dessas situações problemáticas e promove a construção de uma ideia mais humana dos empreendimentos científico e tecnológico (REIS, 1997, 2004; ZEIDLER, 2003). Para além disso, esta abordagem promove a construção de conhecimentos científicos, a compreensão do papel da ciência e da tecnologia na sociedade e o desenvolvimento cognitivo, social, político, moral e ético dos alunos (LEVINSON, 2006; REIS, 1997, 2008a; SADLER, 2004; ZEIDLER, 2003).

Actualmente, as influências do movimento CTS são evidentes nos currículos de ciência portugueses, tanto do Ensino Básico como do Ensino Secundário. As orientações curriculares para o $3^{\circ}$ Ciclo do Ensino Básico, relativas à área disciplinar de Ciências Físicas e Naturais (FREIRE; GALVÃO, 2004; GALVÃO, 2001; GALVÃO; ABRANTES, 2005; GALVÃO; FREIRE, 2004) prevêem a construção de conhecimento (substantivo, processual e epistemológico) sobre a ciência enquanto empreendimento humano, em interacção com a tecnologia e a sociedade, com potencialidades e limitações na resolução de problemas pessoais, sociais e ambientais. Para o desenvolvimento destas competências, as orientações curriculares propõem a vivência de um leque diversificado de experiências educativas, centradas preferencialmente em temas actuais, interessantes e relevantes para os alunos, tais como discussão de assuntos controversos, realização de investigações pelos alunos, análise de relatos de descobertas científicas, resolução de problemas, entre outras. O programa de Biologia e Geologia para os $10^{\circ}$ 
e $11^{\circ}$ anos do Curso Geral de Ciências Naturais (PORTUGAL, 2001) refere como objectivos comuns ao ensino das ciências experimentais:

[...] fornecer uma visão integradora da ciência, estabelecendo relações entre esta e as aplicações tecnológicas, a sociedade e o ambiente" e "fomentar a participação activa em discussões e debates públicos respeitantes a problemas que envolvam a ciência, a tecnologia, a sociedade e o ambiente. (PORTUGAL, 2001, p. 8).

Contudo, a mudança não depende exclusivamente de alterações curriculares, tornando-se necessário um investimento na formação de professores e na construção e validação de recursos educativos adequados (MARTINS, 2002). E, de facto, vários estudos ilustram que, de uma maneira geral, aos professores falta uma compreensão sobre a natureza da ciência e acerca do funcionamento do empreendimento científico (FERNÁNDEZ et al., 2002; LEDERMAN, 1992; McCOMAS, 2000) e que lhes falta, também, conhecimento de conteúdo e didáctico necessário para um ensino explícito da natureza da ciência (REIS, 2004, 2008a; REIS; GALVÃO, 2004; REIS; RODRIGUES; SANTOS, 2006). Para além disso, revelam que os professores estão fortemente ligados a uma tradição transmissiva de factos ou produtos finais da ciência e que, de um modo geral, negligenciam a forma como este conhecimento é construído (GALLAGHER, 1991; McCOMAS; CLOUGH; ALMAZROA, 2000), não incluindo nas suas planificações questões de natureza da ciência (ABD-EL-KHALICK; BELL; LEDERMAN, 1998). Consequentemente, para a maioria dos alunos, a descrição da natureza da ciência limita-se a comentários breves sobre alguns parágrafos do início dos manuais (BENTLEY; GARRISON, 1991).

Ora, cabe aos professores estabelecer a ponte entre a cultura associada à comunidade de cientistas e o resto da sociedade através da iniciação dos alunos em determinados aspectos da cultura científica. Mas como, se durante a sua formação inicial e contínua, os professores raramente têm oportunidade de reflectir sobre aspectos da natureza da ciência (McCOMAS; CLOUGH; ALMAZROA, 2000)? E que tipo de formação favorece o seu conhecimento sobre a natureza da ciência?

O BioQuest ${ }^{4}$ é um projecto que tem como principal objectivo contribuir para a construção de uma interpretação crítica do mundo actual nas suas dimensões científica e tecnológica, evidenciando aspectos ambivalentes da ciência e da tecnologia e as suas interacções profundas com a sociedade e o ambiente. Para tal, desenvolveu um conjunto de actividades de reflexão e discussão sobre controvérsias sociocientíficas actuais (por exemplo, construção da hidroeléctrica de Alqueva, células estaminais, clonagem, estações eólicas), através das quais procura estimular o desenvolvimento de uma literacia científica e promover conhecimentos, capacidades de pensamento crítico e de atitudes e valores que facilitem o envolvimento activo, construtivo e responsável dos cidadãos na sociedade.

Este projecto emergiu de uma linha de investigação e de intervenção centrada na utilização de controvérsias sociocientíficas no ensino das ciências, que se, por um lado apon-

${ }^{4}$ Disponível em: <http://nonio.eses.pt/bioquest/>. 
A discussão de controvérsias sociocientíficas ...

tava para as potencialidades deste tipo de actividades para as aprendizagens dos alunos (REIS, 1997, 1999, 2001), evidenciava, por outro, as dificuldades dos professores em tornar explícito a dimensão da natureza da ciência nas suas práticas (REIS, 2004, 2008a; REIS; GALVÃO, 2004; REIS; RODRIGUES; SANTOS, 2006). Tendo em conta estas evidências, o BioQuest foi, pois, criado com o objectivo duplo de construir, avaliar e divulgar materiais educativos com sugestões de actividades de discussão de questões sociocientíficas (destinadas a áreas curriculares disciplinares e não disciplinares) e de apoiar os professores durante a concepção e implementação deste tipo de actividades nas suas aulas.

Tendo em conta este objectivo, esta metodologia (de discussão de questões sociocientíficas controversas) foi desenvolvida com os professores-formandos da disciplina de Trabalho de Projecto do Mestrado em Educação do Instituto de Educação da Universidade de Lisboa. Pretendia-se não só que os professores melhorassem seu conhecimento de conteúdo sobre questões relacionadas à natureza da ciência, mas também que vivessem situações de aprendizagem inovadoras, facilitando o desenvolvimento de novas expectativas e de atitudes em relação ao ensino das ciências e, eventualmente, a adopção de novas estratégias de ensino. A literatura recente sobre a formação de professores ilumina a importância da reflexão e daí a preocupação em criar estas experiências de aprendizagem e, também, de criar situações que levem os professores a reflectir sobre o tipo de experiência (na qualidade de professores-formandos) e sobre a metodologia de aprendizagem (na qualidade de professores). Com este artigo pretendemos perceber quais as potencialidades educativas que estes professores atribuem a este tipo de metodologia, nomeadamente, como a viveram e que vantagens encontram nela.

\section{Metodologia}

\section{Participantes}

Participaram no estudo 29 professores-formandos de duas turmas distintas (de dois anos diferentes) da disciplina de Trabalho de Projecto do Mestrado em Educação do Instituto de Educação da Universidade de Lisboa. Os professores-formandos tinham diferentes níveis de experiência profissional, encontrando-se em diferentes fases de desenvolvimento profissional. Para além disso, tinham uma formação científica inicial distinta: Português, Filosofia, Matemática, Educação Visual, História, Ciências Naturais, Ciências Físico-Químicas, Biologia e Geologia.

No âmbito da disciplina, foi-lhes pedido que discutissem e reflectissem sobre a construção da hidroeléctrica de Alqueva que originou uma albufeira com cerca de $250 \mathrm{~km}^{2}$ (o maior lago artificial da Europa) e permitiu armazenar um volume total de 4150 milhões de $\mathrm{m}^{3}$ de água. Muitas pessoas vêem-na como uma revolução agrícola e turística para a região do Alentejo (tradicionalmente seca e árida) e para todo o sul de Portugal. Contudo, outras pessoas consideram que a sua imensa albufeira provocou uma catástrofe ambiental e cultural, acabando com milhares de plantas e animais e com diversos espaços arqueológicos. As hidroeléctricas são fundamentais na gestão dos recursos hídricos e na produção de energia de forma não poluente. Contudo, representam sempre uma violenta perturbação dos equilíbrios naturais, destruindo o património natural e cultural e suscitando fortes impactos biológicos, geológicos, climáticos, agrícolas, sociais e económicos. Logo, qualquer processo decisório relativo à cons- 
Galvão, C.; Reis, P., Freire, S.

trução de uma hidroeléctrica envolve sempre uma interacção extremamente complexa de elementos sociais, económicos, científicos, tecnológicos e políticos.

$\mathrm{Na}$ actividade proposta, os participantes foram convidados a analisar informação sobre este tema (proveniente de diversas fontes: a empresa gestora do projecto, organizações ambientalistas, órgãos de comunicação social, artigos científicos de cientistas, etc.) com a finalidade de se pronunciarem acerca das potencialidades e limitações deste empreendimento. Em primeiro lugar, os professores-formandos leram, fora da aula, todos os textos disponibilizados no site, centrados na análise de um conjunto de impactos do empreendimento (naturais, culturais ou sócio-económicos). Já na aula, a turma foi dividida em dois grupos, ficando cada um dos elementos de cada grupo responsável por investigar mais aprofundadamente um dos textos. Posteriormente, com base no contributo de todos os elementos, o grupo discutiu os diferentes textos e impactos e tomou uma decisão, tão consensual quanto possível, sobre o empreendimento (Favorável; Favorável, mas sob determinadas condições; Desfavorável). As decisões finais, bem fundamentadas, foram então apresentadas à turma e novamente discutidas no grande grupo

\section{Método de recolha de dados}

O estudo realizado é de natureza interpretativa, com recurso à análise de narrativas dos professores-formandos como processo de recolha de dados. A narrativa faz parte da nossa vida, pois é através do que contamos que interagimos com os outros, partilhamos acontecimentos e somos mediadores num processo de resignificação das experiências vividas que, segundo Bruner (1991), não só retrata, mas constitui a própria realidade. A narrativa apresenta, deste modo, múltiplas potencialidades como método de investigação e como processo de reflexão pedagógica e de formação (GALVÃO, 2005; REIS, 2008b), uma vez que traz à luz, de uma forma bastante profunda, a experiência relatada e interpretada por alguém, num processo de reflexão que enriquece o acontecimento primário. Considerando o domínio da escola, a narrativa permite aceder ao conhecimento profissional do professor em determinada fase do seu percurso e desenvolvimento (FREITAS; GALVÃO, 2007; GALVÃO, 1998; GALVÃO; FREIRE, 2001; ROSA; GALVÃO, 2006) e é, também, um método útil para analisar concepções sobre ciência e sobre a natureza da ciência e identificar possíveis razões para essas concepções (REIS; GALVÃO, 2004, 2006, 2007; REIS; RODRIGUES; SANTOS, 2006).

No estudo apresentado neste artigo, a narrativa foi o método utilizado para recolha de dados, trazendo não só a perspectiva metodológica, mas também a reflexão sobre as potencialidades da estratégia levada a cabo, em que a discussão constitui uma componente importante.

\section{Método de análise de dados}

O estudo envolveu a análise das 29 narrativas elaboradas pelos professores. Neste artigo, optou-se por se apresentar uma síntese da análise global das 29 narrativas, tendo em conta os elementos comuns. Para além disso, optou-se pela apresentação e análise aprofundada de duas narrativas completas, que foram seleccionadas tendo em conta a riqueza da informação veiculada. 
A discussão de controvérsias sociocientíficas ...

\section{Resultados}

\section{Síntese da análise global das narrativas}

A análise do conjunto das narrativas redigidas pelos professores revela alguns dados interessantes. Foi com alguma surpresa que constatámos nos relatos dos professores a confirmação do desconhecimento real sobre as implicações da construção da hidroeléctrica de Alqueva. Várias afirmações revelam como a actividade de discussão lhes permitiu conhecer diversos aspectos/dimensões deste empreendimento de que nunca se haviam apercebido, apesar de conhecerem a situação em discussão recente no nosso país. Esta situação evidencia algum alheamento destes professores das várias discussões em torno da hidroeléctrica de Alqueva divulgadas pelos media.

Para se pronunciarem positiva ou negativamente quanto ao empreendimento, os professores analisaram todas as informações disponibilizadas pelo BioQuest, contrapondo os argumentos de diversos intervenientes na discussão pública. Esta análise permitiu-lhes conhecer dimensões da controvérsia que desconheciam até então. Apesar de todos os conhecimentos apropriados, muitos professores não se sentiram capacitados para uma tomada de posição. Curiosamente, a dificuldade aumentava à medida que interpretavam os textos e as informações se tornavam mais completas. Cada novo argumento vinha perturbar possíveis decisões alcançadas, impedindo ou dificultando uma tomada de posição clara. Perante as listas extensas de vantagens e inconvenientes, os professores formandos revelaram grandes dificuldades em assumir uma posição. Muitos sentiram necessidade de um contacto directo com o empreendimento que permitisse a obtenção de mais informação (nomeadamente, sobre as repercussões na vida dos habitantes locais) e de informação em primeira-mão, surgindo então propostas de visitas aos locais afectados ou de desenvolvimento de projectos escolares sobre esta controvérsia.

Algumas narrativas revelavam algum sentimento de impotência pessoal e colectiva perante controvérsias deste tipo. Esta é uma dimensão extremamente importante e a que nem sempre damos o devido valor, na ânsia de demonstrar o efeito positivo da participação dos cidadãos. Subjacente às discussões públicas de assuntos controversos, existe a ideia de que a intervenção dos cidadãos (informando-se, discutindo e tomando posição, por exemplo, através de manifestação ou do voto) interfere com decisões políticas. Mas, até que ponto é real esta ideia?

As questões controversas são uma problemática complexa. É um assunto que mostra afinal que a ciência não é tão "bonitinha" e imparcial como se quer fazer parecer.

[...] Onde se encontra a verdade que diそ, respeito à ciência? E vem essa verdade "à tona" com as controvérsias [socio]científicas? Qual dos lados da controvérsia tem a razão? Qual dos lados da controvérsia apresenta os melhores argumentos sem ter a razão? E porque é importante discutir estes assuntos? E até que ponto somos, enquanto cidadãos e não cientistas, capazes de o fazer?

[...] E até que ponto sentem ou não os cidadãos que as argumentações apenas são tentativas de alguém lhes atirar "areia para os olhos"? De que forma devem ser as controvérsias cientificas debatidas pela população? Sem dúvida isto deve ser realizado com a consciência de que a população entende o que está a ser debatido, 
compreende os termos e os argumentos cientificos que estão a ser utilizados. E que estes são usados com veracidade e não enquanto instrumentos de poder. (Maria)

Esta opinião de uma participante no estudo constitui um bom exemplo das preocupações de alguns professores formandos que desencadearam algum desconforto relativamente às nossas eventuais pré-concepções sobre o assunto. Até que ponto a complexidade destas controvérsias poderá comprometer o envolvimento dos cidadãos na sua discussão?

\section{Potencialidades educativas das actividades do BioQuest: evidências das narrativas de professores}

Conforme já foi referido, nesta secção apresentamos dois exemplos completos de narrativas redigidas pelos professores, seguidas da sua análise. Através desta análise pretendemos obter evidências das potencialidades educativas atribuídas pelos professores às actividades do BioQuest, nomeadamente à actividade de discussão da hidroeléctrica de Alqueva. Assinalamos no texto as frases que nos parecem mais significativas para uma exploração posterior.

Narrativa da Isabel:

Actividades pedagógicas de discussão em interacção e cooperação de pares

A discussão gerada em torno das dimensões patrimoniais, naturais, sociais e económicas de construção da barragem do Alqueva permitiu o desenvolvimento partilhado de uma mais fundamentada consciência (A) acerca das consequências da implementação do projecto, quer das benéficas para o desenvolvimento local, quer das adversas ao património cultural e natural e ao tecido social. $A$ discussão entre os diversos elementos do grupo iniciou-se com um tempo de estudo individual autónomo $(B)$, a partir de recursos previamente elaborados pelo professor, que assumiu nesta fase um papel de orientador da tarefa. Nesta fase cada elemento desenvolveu conhecimentos relativos à dimensão do empreendimento sobre a qual se debruçou, reflectindo sobre as vantagens e consequências negativas da intervenção [...].

A fase de discussão entre todos os elementos do grupo, a que correspondiam diversas dimensões de reflexão sobre a barragem, permitiu desenvolver conjuntamente um mais amplo conhecimento reflexivo sobre aquela construção, em todas as dimensões estudadas (C). Desse conbecimento alargado nasceram tendências pessoais afirmativas e negativas relativas à construção da barragem, mas mais interessante foi a determinação das condições especiais na qual ela deveria ter ocorrido, sem prejuízo das suas vantagens para o desenvolvimento económico local. Neste processo de discussão desenvolveram-se competências (D1) de comunicação, reflexão e interação no grupo, avaliando cada dimensão do problema em diálogo com os restantes.

Em todos os momentos da tarefa, o professor assumiu um papel de exclusiva orientação e gestão do processo (E), embora a prévia preparação dos recursos pedagógicos tenha sido determinante para o desenvolvimento de competências de cada elemento/dimensão da tarefa. 
A discussão de controvérsias sociocientíficas ...

Esta metodologia de trabalho permite o desenvolvimento de competências de autonomia na aprendizagem, de reflexão, de comunicação e de interação cooperativa. Cada elemento do grupo é cooperativamente responsabilizado com uma parte da tarefa na qual deve desenvolver competências especificas que, em grupo, permitirão uma reflexão global partilhada e socializada. Deste modo, não havendo sobreposição de tarefas no grupo, cada elemento assume um papel diferenciado sob o qual coopera na tarefa comum. Toda a tarefa está centrada no trabalho dos alunos (F): em trabalho de estudo individual autónomo, num primeiro momento, e finalmente, na discussão fundamentada do problema no grupo [...].

Já havia associado esta metodologia com a Aprendizagem por Problemas (APP) [...] Também o problema proposto ao grupo (Barragem do Alqueva, sim ou não?), tal como na metodologia APP, é um problema suficientemente complexo para que haja a necessidade de estudo e investigação individual para fundamentar uma opção reflexiva e civicamente responsável. O desenvolvimento de competências especificas em trabalho de estudo autónomo individual e a sua consequente comunicação ao grupo induz cada um dos elementos a uma participação efectiva e cooperativa na tarefa, o que atribui maior significado às aprendizagens e promove o envolvimento na resolução do problema.

O papel do professor [...] caracteriza-se pela preparação e gestão da tarefa, sendo ele próprio um recurso para esclarecimento de conceitos mais complexos de que alguns elementos possam necessitar (tutoria) (E). Em contexto de aprendizagem escolar, o professor fica deste modo liberto para atender à especificidade de dificuldades de aprendizagem de alguns elementos do grupo. A heterogeneidade dos grupos (G) pode inclusive ser ponderada pelo professor na planificação das tarefas e diversidade de papéis a atribuir aos seus diversos elementos, adequando a sua complexidade reflexiva às características individuais dos elementos do grupo.

A discussão gerada no grupo alargado em torno da complexidade de análise do problema permite o desenvolvimento de múltiplas competências de trabaIho (D2): a comunicação, o respeito e a tolerância pelo pensamento fundamentado do outro, a tentativa de construção de um espaço de consenso relativamente ao problema, a coesão socializada do grupo em torno de objectivos partilhados. [...]

Todo este processo difere em muito da tradição portuguesa relativa aos processos de aprendizagem em contexto formal (H). Com efeito, nesta metodologia de trabalho o professor deixa de recitar e dominar o discurso, ainda que promova intervenções dos alunos, normalmente em jeito de pergunta resposta. Discutindo entre si um problema, os alunos não receiam avançar respostas a questões levantadas pelos seus pares, sobretudo se as suas experiências prévias tiverem sido enriquecidas e orientadas pelos recursos disponibilizados pelo professor. Por outro lado, tanto os consensos socializados no grupo como as divergências fundamentadamente enunciadas, promovem o desenvolvimento de competências reflexivas generalizáveis a outros contextos de cidadania, quer formais, quer informais (D3). Trata-se de promover a capacidade de escutar e reflectir sobre pontos de vista diferentes, analisada a pertinência da sua fundamentação e grau de compreensão global dos problemas. Trata- 
Galvão, C.; Reis, P., Freire, S.

se de exercer democraticamente a participação social, em responsável compreensão de conceitos prévios a desenvolver. Trata-se ainda de educar para a necessidade de estudo individual prévio à emissão de opiniões (I), tantas vezes emitidas mas pouco fundamentadas pelos nossos cidadãos, sobretudo numa sociedade em permanente desenvolvimento tecnológico e cientifico, na qual muitas das aprendizagens ao longo da vida podem já ser efectuadas individualmente. Este é para mim, aliás, o aspecto mais significativo desta metodologia de trabalho: a capacidade de tornar os alunos co-produtores do conhecimento um conhecimento individual, mas também social. É pois com muito interesse que perspectivo a criação de estruturas pedagógicas de projecto e desenvolvimento de conbecimentos especificos relativos à minha disciplina escolar, receando contudo a incapacidade de gerar tantos recursos quanto necessários ao desenvolvimento de trabalho pelos alunos em função dos conteúdos a abordar. Terá de ser um percurso, iniciando um progressivo caminho de criação, avaliação $e$ reformulação de recursos a que os alunos possam recorrer no âmbito dos projectos de trabalho criativo da disciplina de Educação Visual. Recordo como no ano lectivo anterior abordei em Formação Cívica o problema da Emigração em Portugal numa turma de $9^{\circ}$ ano na qual havia alguns comportamentos de simpatia neo-nazi: apresentei recursos, tantas vezes adiantando eu própria a sua leitura e análise, antecipando uma discussão que não se fazia, provavelmente pela esperada visão "certa" da professora. Afinal, há que lançar alguns dados e esperar, em silêncio, que a interacção germine, motivada por recursos apelativos e problemas pertinentemente enunciados.

Esta narrativa apresenta todo um processo reflexivo que se vai complexificando desde: (1) a experiência vivida, e como tal considerada o primeiro nível de representação da realidade (RIESSMAN, 1993), analisada nas competências que sentiu desenvolver como aluna; (2) às interacções estabelecidas na própria sala de aula, como professora orientando os seus alunos, numa disciplina particular; e (3) culminando numa análise mais lata de potencialidades educativas numa escola possível. O próprio título da narrativa reflecte as dimensões a que a professora atribui maior relevância na tarefa: Discussão, interaç̧ão e cooperação. Toda a reflexão segue o percurso das vantagens desta associação, colocando a discussão numa posição metodológica central a um processo de resolução de problemas (a analogia com a APP é disso exemplo). $\mathrm{O}$ texto desenvolve-se numa primeira fase em várias componentes, assinaladas por nós de (A) a (D), com algumas frases em negrito, em que são evidenciadas as fases do trabalho, associadas às competências (D1) que cada uma permite desenvolver. Numa segunda fase do texto, temos uma reflexão sobre o significado desta metodologia, em que Isabel refere o papel do professor (E) em dois momentos, na orientação dos alunos no desenrolar da tarefa e na preparação necessária desta, em contraponto ao papel do aluno identificado a seguir (F). Nessa reflexão está também inerente a natureza dos grupos (G). Noutro nível de reflexão, a professora discorre novamente sobre as competências associadas à tarefa na sua globalidade (D2 e D3), destacando as suas vantagens relativamente ao ensino tradicional (H). Toda a última parte do texto se enquadra neste nível de análise, profundo e prospectivo de uma escola que devia existir. É de destacar, quase como conclusão, a frase em que Isabel apresenta como ilação maior a necessidade de educação para um estudo prévio à emissão de opiniões, para que 
A discussão de controvérsias sociocientíficas ...

estas sejam fundamentadas (I). A frase em negrito (dela) é também uma conclusão sobre o significado deste tipo de tarefas para a aprendizagem socializada dos alunos. A pequena história apresentada no final é o corolário da sua própria aprendizagem, evidenciando a necessidade de criar oportunidades de discussão, livres de "respostas desejadas", que facilitem "o desenvolvimento partilhado de uma mais fundamentada consciência".

\section{Narrativa do Rafael - Discutindo a hidroeléctrica de Alqueva}

A abordagem da actividade de discussão, "Discutindo a bidroeléctrica de Alqueva", através da sua realização no papel de aluno foi bastante importante, dado ter permitido aferir sobre eventuais dificuldades que os alunos podem sentir na realização da mesma e simultaneamente reflectir, enquanto professor, sobre a utilização deste tipo de actividades no contexto de sala de aula (A1). A realização da actividade permitiu assim uma análise sobre duas perspectivas, de aluno e de professor, que de outro modo seria praticamente impossivel de ocorrer, uma vez que quando era aluno a preocupação estava direccionada para a realização da actividade e não a avaliar as potencialidades da actividade, sendo que enquanto professor na planificação de uma actividade com estas características poderei analisar a informação tal como os alunos e ponderar diferentes perspectivas sobre o assunto em discussão, mas muito dificilmente terei a possibilidade de realizar a discussão e verificar eventuais limitações que a actividade possa ter e que apenas são detectadas aquando da discussão (A2). Salientando contudo a consciência de que, mesmo que tal fosse possivel, iriam sempre existir situações imprevisíveis (A3), principalmente pelo facto deste tipo de actividade envolver argumentos de diferentes áreas cuja valorização está dependente dos alunos e dos seus valores.

$\mathrm{Na}$ realização desta actividade um dos aspectos mais relevantes foi precisamente verificar a diferente valorização atribuída aos diferentes argumentos por cada interveniente na discussão (B), sendo notório que a menor ou maior valorização estava associada principalmente à área de formação de cada um. Transferindo essa situação para uma actividade realizada com alunos, esta situação é reveladora da importância da constituição de grupos de discussão heterogéneos, pois será um modo de criar mais condições para os diferentes argumentos serem discutidos, dado que os alunos irão ter interesses e conbecimentos provenientes de fontes diferentes e poderão contribuir assim para discussões mais estimulantes.

No percurso de estudante, incluindo a formação inicial de professor, não realizei em muitas ocasiões actividades de discussão (C1). [...] Contudo, apesar de não ter tido um contacto muito frequente com este tipo de metodologia ao longo da minha formação, identifico um vasto e importante conjunto de potencialidades a este tipo de metodologia, sendo uma metodologia que pretendo vir a utilizar nas aulas com os meus alunos. Todavia, muito provavelmente, por não ter tido muita experiência enquanto aluno com estas metodologias e ter por vezes ainda alguma insegurança $e$ 
Galvão, C.; Reis, P., Freire, S.

necessidade de evitar situações com demasiados imponderáveis, terei nas primeiras vezes que utilizar esta metodologia algumas precauções na escolha da turma (C2), nomeadamente que sejam constituidas por alunos que apresentem já algumas competências e atitudes relacionadas com trabalho em grupo. Considero que assim poderei gerir melhor os imprevistos que surjam e em situações futuras implementar de um modo mais seguro em outras turmas nos quais os alunos não apresentem à partida competências características deste tipo de actividades muito desenvolvidas.

Apesar do conhecimento sobre a metodologia de discussão se encontrar sobretudo ao nivel das leituras e não tanto na sua realização ou implementação nas aulas, considero que esta metodologia tem efectivamente importantes potencialidades educativas, nomeadamente ao nível do desenvolvimento do pensamento crítico, da interpretação de informação, de argumentação, da tomada de decisão, de competências de comunicação e também na própria aquisição de conhecimento substantivo (D1). Realço também a importância das discussões no desenvolvimento de atitudes e competências sociais, particularmente o saber ouvir e respeitar os outros. Uma das maiores potencialidades deste tipo de actividades será também o facto de permitir aproximar a Ciência que é abordada em sala de aula dos problemas da sociedade (D2), ou seja, dos problemas com que os alunos se deparam no seu dia-a-dia e que os afecta directa ou indirectamente, permitindo assim que os alunos reflictam e abordem esses problemas, que também são seus e se venham assim a desenvolver como cidadãos activos e conscientes dos problemas da sociedade. Refira-se que, das categorias referidas anteriormente para as actividades de discussão, serão as questões controversas, como a realizada na aula, as que maior impacto considero terem ao nivel da motivação dos alunos, pois são assuntos muitas vezes motivo de conversa nas próprias famílias e através da abordagem destes temas na escola os alunos poderão esclarecer-se sobre os mesmos e "levar" esse conhecimento para as suas famílias (D3) tornando as referidas conversas em algo mais do que troca de opinioes pouco informadas. Para além do já referido, um outro aspecto importante relacionado com esta metodologia corresponde à atribuição de uma maior autonomia e responsabilidade aos alunos, tornando-os mais activos e intervenientes na abordagem dos temas em estudo e assim no seu processo de aprendizagem $(\boldsymbol{E})$. Ao conferir-se um papel mais central ao aluno, não só na discussão, mas na relação entre os alunos e a informação disponivel o professor terá claramente um papel que poderá considerar-se menos central, mas certamente não menos importante ou menos trabalhoso, uma vez que irá ter um papel de moderador $(F)$, auxiliando-os na sua interpretação e fornecendo-lhes orientações, tendo também um importante papel na gestão do tempo conferido a cada uma das etapas da actividade [...].

A discussão, pelo facto de envolver a interaç̧ão de diferentes pessoas que têm um objectivo comum, encontra-se directamente relacionada com outras metodologias $(\boldsymbol{G})$ que envolvam a tomada de decisões devidamente fundamentadas [...] Atendendo-se aos conceitos que foram considerados como funda- 
mentais no trabalho de projecto, no decurso das aulas, nomeadamente o de negociação e de cooperação, [...] tendo em vista uma resposta que reúna consenso e que seja considerada como a mais satisfatória.

Em suma, considero que as actividades de discussão contribuem para o desenvolvimento de um conjunto vasto de competências nos alunos, contribuindo para que compreendam melhor o mundo que os rodeia, bem como a estarem mais receptivos a informações e opiniões de outras pessoas, sabendo interpretá-la e assim enriquecer a sua própria compreensão sobre um determinado assunto. Realço por último que a utilização deste tipo de actividades também permitirá aos alunos uma melhor preparação para a sua entrada no mundo profissional e para viverem em sociedade, uma vez que em todas as áreas profissionais existem decisões que têm de ser tomadas de um modo fundamentado e após análise de diferentes perspectivas, ou seja, através de discussões.

Encontramos na narrativa do Rafael, três aspectos fundamentais relacionados com o seu percurso pessoal e profissional: a vivência da actividade na dupla perspectiva de aluno e de professor (A), visto tratar-se de uma pessoa muito jovem que terminou a sua formação inicial há pouco tempo; a sensibilização relativamente à necessidade de analisar os diferentes aspectos do mesmo problema (B); o reconhecimento do facto de nunca ter experimentado como aluno uma situação deste tipo (C). São três aspectos marcantes que fazem desenrolar toda a reflexão, nomeadamente sobre as potencialidades educativas (D), onde inclui o desenvolvimento do pensamento crítico, das capacidades de argumentação e de tomada de decisão. Outra potencialidade referida consiste na aproximação da Ciência aos alunos (e, eventualmente, às suas próprias famílias) pela abordagem de situações do dia-a-dia.

Rafael reflecte também sobre o papel dos alunos (E) e do professor (F) na tarefa, discutindo o significado das vantagens para uns e outro, sem deixar de frisar a necessidade de uma boa planificação. Fica patente a insegurança que esta metodologia ainda lhe provoca, precisamente pela sua falta de experiência. O jovem professor, num nível de análise mais global, compara a discussão com outras metodologias, fazendo um paralelismo com trabalho de projecto, quer na perspectiva metodológica quer numa perspectiva mais conceptual, em que a negociação e a cooperação estão associadas. Termina com um parágrafo síntese, retomando as potencialidades educativas numa perspectiva mais lata de formação de cidadãos para o mundo em que vivem e para as profissões que virão a desempenhar. Trata-se de uma reflexão que parte do particular, a sua própria vivência, para o geral, os alunos como cidadãos.

\section{Conclusões}

Deste estudo emergem quatro aspectos fundamentais que evidenciaremos e discutiremos de seguida:

1. Na opinião dos professores que nela participaram, a actividade realizada evidencia a importância da discussão de assuntos sociocientíficos, pelo confronto de argumentos contrastantes, pela oportunidade de construção e aprofundamento de conhecimentos e por constituir um contexto e um pretexto para novas pesquisas e actividades educativas; 
2. Os assuntos sociocientíficos, como a construção da barragem de Alqueva, envolvem uma dimensão social extremamente forte com a qual as pessoas se identificam, facilitando a discussão e a compreensão da Ciência e da Tecnologia associadas e das suas múltiplas interacções com a Sociedade e o Ambiente. Com a discussão deste tipo de assuntos, não se pretende promover a aceitação cega da Ciência e da Tecnologia, nem combatê-las com argumentos obscurantistas. Pretende-se sim, promover a compreensão dos seus aspectos controversos e a análise dos argumentos apresentados por diferentes intervenientes. Desta forma, o aluno não é confrontado com um discurso moralista ou faccioso sobre, por exemplo, problemáticas ambientais. Pelo contrário, é confrontado com uma diversidade de informações, argumentos e opiniões perante as quais deverá construir uma opinião (e, eventualmente, tomar uma decisão) fundamentada. Decide em função daquilo que considera ser melhor para todos e não apenas para si próprio, havendo uma dimensão colectiva na discussão de assuntos sociocientíficos que é preciso realçar, mesmo no caso de o colectivo não dispor de um poder político real tão forte como à partida podemos ser levados a pensar.

3. A Narrativa trouxe a possibilidade de se entender o modo de apropriação do que foi discutido, de como a controvérsia foi vivida e analisada por cada participante. A Narrativa trouxe-nos de um modo diferenciado - porque pessoal -, os sucessivos patamares de entendimento da situação problemática, permitindo ir mais longe na projecção que cada um faz na sua própria realidade profissional.

4. O processo de reflexão inerente ao pensamento sobre um acontecimento e à sua narração, implica uma maior consciência dos impactos dos assuntos, das experiências, das memórias, dos percursos pessoais, na pessoa de hoje (aquela que pensa e escreve sobre determinada problemática). Estamos convictos de que se trata de um processo de desenvolvimento pessoal extremamente forte com repercussões no desenvolvimento profissional.

As potencialidades da discussão de assuntos sociocientíficos ficaram bem evidentes nas narrativas dos professores formandos. O sentimento da relevância e da importância da ciência para todos pode ser reforçado através de actividades como a que descrevemos. Estas actividades fornecem um contexto no qual os conhecimentos científicos assumem um maior sentido e onde, simultaneamente, se estimula a necessidade da construção de mais conhecimento e se desenvolvem competências indispensáveis a uma aprendizagem ao longo da vida. A narrativa trouxe-nos a dimensão da apropriação dos professores formandos sobre a actividade em si e as potencialidades educativas da discussão das controvérsias sociocientíficas que, de outro modo, teríamos muita dificuldade em obter com tanta clareza. Paralelamente, a narrativa constituiu um método de desenvolvimento profissional de todos os envolvidos: tanto daqueles que reflectiram e escreveram - os professores formandos - como daqueles que leram e reflectiram - os professores investigadores.

E é precisamente como investigadores que importa ainda reflectir, de um modo prospectivo, sobre os verdadeiros impactos de uma metodologia como esta nos professores e nas suas práticas. Não temos dúvida, pelos seus relatos, que estes professores viveram uma nova situação de aprendizagem, evidenciando compreensão da importância de discutir a natureza do conhecimento científico. Mas esta experiência que eles vivem, que avaliam muito positivamente (conforme evidenciado pelas suas narrativas) é suficiente para mudar as suas práticas? E o que realmente mudou neles? Mudaram as suas concepções sobre o que deve ser o ensino nas ciências? Sobre quais devem ser as finalidades das ciências? Os professores desenvolveram, com esta actividade, conhecimento didáctico que lhes permita incluir explicitamente a 
A discussão de controvérsias sociocientíficas ...

dimensão natureza da ciência nas suas aulas? E terão desenvolvido conhecimento substantivo sobre a natureza da ciência? Ou foi uma experiência interessante, que os alertou para aspectos para os quais não tinham pensado (pelo menos de forma sistemática), e que tem o seu valor... mas fica aquém daquilo que se pretende em termos do desenvolvimento profissional dos professores, ou da aprendizagem que pretendemos que eles façam. Todas estas questões abrem outras perspectivas de investigação, por exemplo, em contexto de sala de aula, permitindo novas abordagens de formação dos professores envolvidos. Não podemos ficar ingenuamente à espera que vivências pontuais desencadeiem mecanismos de mudança, embora saibamos que, por vezes, há episódios narrados por outros, experiências que alguém viveu e partilha, que provocam dúvidas sobre práticas pessoais e estimulam reflexão que ajuda ao questionamento. Temos consciência que é um princípio que é preciso agarrar para continuar a investir de uma forma mais sistemática e profunda.

\section{Referências}

ABD-EL-KHALICK, F.; BELL, R.; LEDERMAN, N. The nature of science and instructional practice: making the unnatural natural. Science Education, Hoboken, v. 82, n. 4, p. 417-437, 1998.

AIKENHEAD, G. What is STS science teaching? In: SOLOMON, J.; AIKENHEAD, G. (Ed.). STS education: international perspectives on reform. New York: Teachers College Press, 1994. p. 47-59.

AIKENHEAD, G. Renegotiating the culture of school science: scientific literacy for an informed public. In: LISBON'S SCHOOL OF SCIENCE CONFERENCE, May 17, 2002, Lisboa. Disponível em: <http://www.usask.ca/education/people/aikenhead/ portugal.htm>. Acesso em: 30 nov. 2010.

AIKENHEAD, G. STS Education: a rose by any other name. In: CROSS, R. (Ed.). A vision for science education: responding to the work of Peter J. Fensham. New York: Routledge Falmer, 2003. p. 59-75.

BENTLEY, V.; GARRISON, J. The role of philosophy of science in science teacher education. Journal of Science Teacher Education, Dordrecht, v. 2, n. 3, p. 67-71, 1991.

BRIDGES, D. Education, democracy \& discussion. Lanham: University Press of America, 1988.

BROOKFIELD, S.; PRESKILL, S. Discussion as a way of teaching: tools and techniques for democratic classrooms. San Francisco: Jossey-Bass Publishers, 1999.

BRUNER, J. The narrative construction of reality. Critical Inquiry, Chicago, v. 18, p. 1-21, 1991. 
Galvão, C.; Reis, P., Freire, S.

DOISE, W. ; MUGNY, G. ; PERRET-CLERMONT, A. N. Social interaction and the development of cognitive operations. European Journal of Social Psychology, Bognor Regis, v. 5, n. 3, p. 367-383, 1975.

FERNÁNDEZ, I. et al. Visiones deformadas de la ciencia transmitidas por la enseñanza. Enseñanza de las Ciencias, Barcelona, v. 20, n. 3, p. 477-488, 2002.

FREIRE, A.; GALVÃO, C. O petróleo como exemplo de um assunto CTSA no currículo. Boletim da APPBG, Lisboa, n. 23, p. 5-12, 2004.

FREITAS, D.; GALVÃO, C. O uso de narrativas autobiográficas no desenvolvimento profissional de professores. Ciências \& Cognição, Rio de Janeiro, v. 12, p. 219-233, 2007. Disponível em: <http://www.cienciasecognicao.org/pdf/v12/m347196.pdf >. Acesso em: 30 nov. 2010.

GALLAGHER, J. J. Prospective and practicing secondary school science teachers' knowledge and beliefs about the philosophy of science. Science Education, Hoboken, v. 75, n. 1, p. 121-133, 1991.

Professor: o início da prática profissional. 1998. 716 f. Tese (Doutorado em Educação) - Faculdade de Ciências, Universidade de Lisboa, Lisboa, 1998.

GALVÃO, C. (Coord). Ciências físicas e naturais: orientações curriculares para o $3^{\circ}$ ciclo do ensino básico. Lisboa: Ministério da Educação, Departamento da Educação Básica, 2001. 2005.

. Narrativas em Educação. Ciência \& Educação, Bauru, v. 2, n. 2, p. 327-345,

GALVÃO, C.; ABRANTES, P. Physical and natural sciences: a new curriculum in Portugal. In: NENTWIG, P.; WADDINGTON, D. (Ed.). Making it relevant: context based learning of science. Münster: Waxmann Verlag, 2005. p. 175-194.

GALVÃO, C.; FREIRE, S. Tornar-se professora no ensino superior. Revista de Educação, Lisboa, v. 10, n. 1, p. 75-85, 2001.

GALVÃO, C.; FREIRE, A. A perspectiva CTS no currículo das ciências físicas e naturais em Portugal. In: MARTINS, I.; PAIXÃO, F.; VIEIRA, R. (Orgs.). Perspectivas ciênciatecnologia-sociedade na inovação da educação em ciência. Aveiro: Universidade de Aveiro, 2004. p. 31-38.

GUTMANN, A.; THOMPSON, D. Democracy and disagreement: why moral conflict can not be avoid in politics, and what should be done about it. Cambridge: Harvard University Press, 1996.

LEDERMAN, N. Students' and teachers' conceptions of the nature of science: a review of the research. Journal of Research in Science Teaching, Hoboken, v. 29, n. 4, p. 331-359, 1992.

LEVINSON, R. The use of narrative in supporting the teaching of socio-scientific issues: a study of teachers' reflections. Interacções, Santarém, v. 2, n. 4, p. 24-41, 2006. 
A discussão de controvérsias sociocientíficas ...

MARTINS, I. Problemas e perspectivas sobre a integração CTS no sistema educativo português. Revista Electrónica de Enseñanza de las Ciencias, Vigo, v. 1, n. 1, p. 1-13, 2002.

McCOMAS, W. The principal elements of the nature of science: dispelling the myths. In: The nature of science in science education: rationales and strategies.

Dordrecht: Kluwer, 2000. p. 53-70.

McCOMAS, W.; CLOUGH, P.; ALMAZROA, H. The role and character of the nature of science in science education. In: McCOMAS, W. (Ed.). The nature of science in science education: rationales and strategies. Dordrecht: Kluwer, 2000. p. 3-39.

OSBORNE, J. Science for citizenship. In: MONK, M.; OSBORNE, J. (Ed.). Good practice in science teaching. Buckingham: Open University Press, 2000. p. 225-240.

PARKER, W.; HESS, D. Teaching with and for discussion. Teaching and Teacher Education, Kidlington, v. 17, n. 3, p. 273-289, 2001.

PEDRETTI, E. Teaching science, technology, society and environment (STSE) education: preservice teachers' philosophical and pedagogical landscapes. In: ZEIDLER, D. L. (Ed.). The role of moral reasoning on socioscientific issues and discourse in science education. Dordrecht: Kluwer, 2003. p. 219-239.

PORTUGAL. Ministério da Educação. Programa de biologia e geologia para os $10^{\circ} \mathrm{e}$ $1^{\circ}$ anos do curso geral de ciências naturais. Lisboa: Ministério da Educação, 2001.

REIS, P. O projecto "GENET": biotecnologia, controvérsias e internet. In: ENCONTRO NACIONAL DE EDUCAÇÃO EM CIÊNCIAS, 7., 1999, Faro. Actas... Faro: Universidade do Algarve, Escola Superior de Educação, 1999. p. 454-458.

REIS, P. O ensino das ciências através da discussão de controvérsias: realidade ou ficção? In: CONGRESSO GALAICO-PORTUGUÊS DE PSICOPEDAGOGIA, 6., 2001, Braga. Actas... Braga: Centro de Estudos em Educação e Psicologia, Universidade do Minho, 2001. p. 367-379.

REIS, P. A escola e as controvérsias sociocientíficas: perspectivas de alunos e professores. Lisboa: Escolar Editora, 2008a.

As narrativas na formação de professores e na investigação em educação.

Nuances: Estudos sobre Educação, Presidente Prudente, v. 15, n. 16, p. 17-34, 2008b.

. Ciência e controvérsia. Revista de Estudos Universitários, Sorocaba, v. 35, n. 2, p. 9-15, 2009. Disponível em: <http://periodicos.uniso.br/index.php/reu/issue/view/40>. Acesso em: 30 nov. 2010.

REIS, P. G. R. Controvérsias sócio-científicas: discutir ou não discutir? Percursos de aprendizagem na disciplina de ciências da terra e da vida. 2004. 472f. Tese (Doutorado em Didáctica das Ciências) - Faculdade de Ciências, Universidade de Lisboa, Lisboa, 2004.

A promoção do pensamento através da discussão dos novos avanços na área da biotecnologia e da genética. 1997. 202f. Dissertação (Mestrado em Educação) Faculdade de Ciências, Universidade de Lisboa, Lisboa, 1997. 
Galvão, C.; Reis, P., Freire, S.

REIS, P.; GALVÃO, C. Socio-scientific controversies and students' conceptions about scientists. International Journal of Science Education, Abingdon, v. 26, n. 13, p. 1621-1633, 2004.

REIS, P.; GALVÃO, C. O diagnóstico de concepções sobre os cientistas através da análise e discussão de histórias de ficção científica redigidas pelos alunos. Revista Electrónica de Enseñanza de las Ciencias, Vigo, v. 5, n. 2, p. 213-234, 2006.

.; ___ Reflecting on scientists' activity based on science fiction stories written by secondary students. International Journal of Science Education, Abingdon, v. 29, n. 10, p. 1245-1260, 2007.

REIS, P.; RODRIGUES, S.; SANTOS, F. Concepções sobre os cientistas em alunos do $1^{\circ}$ ciclo do ensino básico: "poções, máquinas, monstros, invenções e outras coisas malucas". Revista Electrónica de Enseñanza de las Ciencias, Vigo, v. 5, n. 1, p. 51-74, 2006.

RIESSMAN, C. Narrative analysis. Newbury Park: Sage, 1993.

ROSA, A.; GALVÃO, C. A prática pedagógica de Alice: futura professora de matemática do $2^{\circ}$ ciclo do ensino básico. In: SEMINÁRIO DE INVESTIGAÇÃO EM EDUCAÇÃO MATEMÁTICA - SIEM, 17., 2006, Lisboa. Actas... Lisboa: SIEM, 2006. 1 cd-rom.

SADLER, T. D. Informal reasoning regarding socioscientific issues: a critical review of research. Journal of Research in Science Teaching, Hoboken, v. 41, n. 5, p. 513-536, 2004.

SOLOMON, J. Teaching science, technology and society. Buckingham: Open University Press, 1993.

VYGOTSKY, L. S. Mind in society. Cambridge: Harvard University Press, 1978.

ZEIDLER, D. L. The role of moral reasoning on socioscientific issues and discourse in science education. Dordrecht: Kluwer, 2003.

ZIMAN, J. An introduction to science studies: the philosophical and social aspects of science and technology. Cambridge: Cambridge University Press, 1984.

ZIMAN, J. The rationale of STS education is in the approach. In: SOLOMON, J.;

AIKENHEAD, G. (Eds.). STS education: international perspectives on reform. New York: Teachers College Press, 1994. p. 21-31.

Artigo recebido em 09/10/2010. Aceito em 25/04/2011. 